\title{
Systemic Hypertension in Heart Transplant Recipients
}

\author{
Miguel Gus, Nádia Schiavo, Altamiro Reis da Costa \\ Porto Alegre, RS - Brazil
}

Heart transplant recipients develop systemic hypertension $(\mathrm{SH})$, which is generally difficult to clinically control, requiring the use of several antihypertensive drugs. The pathophysiology involves the action of cyclosporine through the following mechanisms: alterations in the renin-angiotensin-aldosterone and sympathetic system, in prostaglandin and thromboxane A2 levels, in plasmatic endothelin action and in renal function associated with vasoconstriction of the renal arterioles. Cyclosporine-induced SH develops regardless of the classic cardiovascular risk factors, which may exist before and after transplantation, but control of these factors is advisable. Calcium antagonists are effective drugs in the treatment of SH in cyclosporine-treated patients and seem to be the antihypertensives of choice. This review shows the pathophysiologic mechanisms and hemodynamic alterations involved in the hypertension of heart transplant recipients, as well as the aspects related to its treatment and prognosis.

Cardiac transplantation has been the treatment of choice for patients with terminal heart failure ${ }^{1-7}$. The understanding of immunological responses to transplanted tissues, as well as the development of immunosuppressive therapy, has contributed to improvement in the results of cardiac transplantation in the last few years. In addition, the improvement in the diagnosis and treatment of infections and the routine use of endomyocardial biopsy, thus allowing monitoring of graft rejection ${ }^{5}$, also play important roles.

Before cyclosporine, immunosuppression following cardiac transplantation was based upon the use of azathioprine and prednisone. Infections and transplanted organ rejection were the main causes of death at that time ${ }^{6}$. Since 1981, with the introduction of cyclosporine in the immunosuppressive therapeutic scheme, short- and long-term survival after cardiac transplantation have been significantly increased ${ }^{5,8,9}$. In a two-year follow-up after transplantation, the survival rate increased from $58 \%$ to $75 \%$ with the use of cyclosporine, when compared with the conventional immunosuppressive therapy (azathioprine and prednisone) ${ }^{10}$.

Instituto de Cardiologia do Rio Grande do Sul/Fundação Universitária de Cardiologia - Porto Alegre

Mailing address: Miguel Gus - Unidade de Pesquisa do IC/FUC - Av. Princesa Isabel, 395 - 90620-001 - Porto Alegre, RS - Brazil
Cyclosporine, a polypeptide derived from fungi, selectively blocks the effect of interleukin-2 and stimulates T-cells. It is a powerful immunosuppressive drug, representing the basis of current immunosuppressive therapy in organ transplant recipients ${ }^{11-13}$. Its use, however, is related to several adverse effects, such as $\mathrm{SH}^{2,5-10,14-23}$, nephrotoxicity $^{2,5-8,11-17,20-23}$, hepatotoxicity ${ }^{8,11}$, neurotoxicity ${ }^{1}$, myocardial fibrosis ${ }^{6,8,12}$, hirsutism, hypertrichosis and gingival hyperplasia ${ }^{11,23}$.

SH and nephrotoxicity are the most common adverse effects ${ }^{9,13}$, more frequent in organ transplant recipients using cyclosporine than in those treated with azathioprine and prednisone ${ }^{1,4,7}$. In these patients, SH occurs in less than $20 \%$ and the incidence of nephrotoxicity is insignificant ${ }^{3,7,17,20}$.

\section{Risk factors}

Conventional demographic characteristics associated with hypertension, such as age, gender, race, obesity and familial history, seem not to influence SH development in cardiac transplant recipients ${ }^{7,17}$. Risk factors existing before transplantation, such as hypertension, smoking and hypercholesterolemia, are not equally related to $\mathrm{SH}$ following cardiac transplantation ${ }^{17}$. Studies have not found any correlation between body weight increase and blood pressure (BP) values ${ }^{9,17}$. Olivari et al ${ }^{9}$, however, showed that the weight increase in normotensive patients following transplantation was smaller than the average weight of all transplanted patients, suggesting that obesity may play an important role in $\mathrm{SH}$ development following cardiac transplantation. The effect of weight reduction on the BP of these patients is not known, but body weight reduction is recommended due to hemodynamic alterations occurring after transplantation. These alterations should be investigated ${ }^{9,17}$.

Cyclosporine-induced $\mathrm{SH}$ develops regardless of the classic cardiovascular risk factors, which may exist before and after cardiac transplantation ${ }^{17,20}$. So far, the risk factors associated with SH development following cardiac transplantation have not been identified.

\section{Cyclosporine and systemic hypertension}

SH has been shown in patients treated with cyclosporine after renal, cardiac, hepatic and bone marrow transplantation, and even in nontransplanted patients receiving cyclosporine due to autoimmune diseases ${ }^{7,14,19}$. 
Cyclosporine-induced $\mathrm{SH}$ is a serious and frequent complication in cardiac transplant recipients ${ }^{1,2,4,24,25}$. It can be detected as early as in the first postoperative week and occurs in nearly 70 to $95 \%$ of the patients ${ }^{1-5,18,26,27}$.

There is no correlation between blood cyclosporine concentration and elevated $\mathrm{BP}{ }^{17}$, and the acute floating of the levels of this drug does not relate to changes in $\mathrm{BP}$ levels ${ }^{14}$

Moderate to severe $\mathrm{SH}$ is generally difficult to control clinically, requiring the use of several antihypertensive drugs ${ }^{7,24}$. This adverse effect of cyclosporine deserves special attention because it is one of the major problems for cardiac transplant recipients ${ }^{24}$. In addition to contributing to the development of coronary heart disease following transplantation, it probably accelerates atherosclerosis in other regions and is related to cerebral stroke, aortic dissection and the appearance of nephropathy after transplantation ${ }^{28}$. These cardiovascular and renal alterations may increase morbidity and mortality in these patients ${ }^{22}$.

\section{Pathophysiology}

Cyclosporine-induced SH pathophysiology is still not well defined but several factors may contribute to its development ${ }^{1,2,5,12,14}$.

Many studies have tried to clarify the pathophysiology of SH arising in cardiac transplant recipients. Cyclosporine-induced SH has been the most studied mechanism. Some of the proposed pathophysiologic mechanisms are alterations in the renin-angiotensinaldosterone and sympathetic systems, in renal function associated with vasoconstriction of renal arterioles, in prostaglandin and thromboxane A2 levels, and in plasmatic endothelin action 1,21,22,29.

Cyclosporine causes a reduction in renal blood flow ${ }^{6,13,21}$, diminishing the glomerular filtration rate ${ }^{13}$. The drug increases plasmatic creatinine and is dose-dependant and reversible. It causes equally disproportional increases in plasmatic urea levels, hyperkalemia, and metabolic acidosis. Chronic interstitial nephritis ${ }^{7,19}$, tubular atrophy ${ }^{20}$ and glomerulosclerosis are observed in a later phase and represent irreversible alterations ${ }^{13,20}$. The mechanisms of these effects are not clear but experimental evidence shows tubular toxicity and action on renal vessels with consequent vascular lesions ${ }^{7}$. The renal tubules are the primary sites of the cyclosporine nephrotoxic effect and nephron function loss could lead to $\mathrm{SH}$ development ${ }^{3,7}$.

Clinical studies have shown that creatinine levels are similar in patients with or without $\mathrm{SH}$ after some days of cardiac transplantation. Renal function may suffer some discrete alteration in the beginning of the treatment with cyclosporine but rapidly deteriorates in the first month ${ }^{30}$. Cyclosporine-induced nephrotoxicity may contribute to $\mathrm{SH}$ arising in cardiac transplant recipients ${ }^{15,52}$. Olivari et al ${ }^{9}$, however, administering low doses of cyclosporine, showed that, two weeks after cardiac transplantation, $68 \%$ of the patients were already hypertensive and the plasmatic creatinine levels were normal. Six months after transplantation, $96 \%$ of the patients were hypertensive, and there was no correlation between BP, creatinine, and serum cyclosporine levels. Even though most of the patients develop SH, despite using cyclosporine in low doses, this drug does not seem necessarily associated with renal function injury ${ }^{9,25}$.

Decrease in glomerular filtration rate causes sodium and water retention, resulting in expansion of the extracellular liquid volume and BP increase ${ }^{3,9,11,12,14,19,20,31,32}$. The presence of normal cardiac output and ventricular filling pressure is an indirect argument against the hypothesis that hypervolemia would be the cause of cyclosporine-induced $\mathrm{SH}^{9}$. There is no strong evidence that plasmatic volume expansion is an important factor in the pathogenesis of this type of $\mathrm{SH}^{22}$.

Hemodynamic changes observed in the kidney probably result from renal vasoconstriction of afferent arterioles ${ }^{2,5,12,21,22,28}$. The BP increase in cardiac transplant recipients using cyclosporine is also associated with high peripheral vascular resistance, suggesting arteriolar vasoconstriction ${ }^{3,4,7}$. Cyclosporine has a vasoconstrictor effect both on the renal arterioles and the peripheral vascular system ${ }^{1,3,9}$.

Cellular and molecular mechanisms responsible for the vasoconstriction caused by cyclosporine are not precisely established. The action of intrinsic vasoconstrictor properties of cyclosporine is suggested as well as the increase in sensitivity of several vasoconstrictor agents ${ }^{14,21}$, such as noradrenaline ${ }^{1,12,15,24}$, angiotensin II ${ }^{1,12,14,15}$, thromboxane A2 ${ }^{1,14,15}$ and endothelin ${ }^{12,14,33}$. As an intrinsic vasoconstrictor action of cyclosporine, its effect on calcium homeostasis ${ }^{19}$ and on a calcium-calmodulin-dependant phosphatase, calcineurin, is being studied. Intracellular calcium is one of the major mediators of smooth muscle contractile response. Cyclosporine would induce vasoconstriction, increasing this ion release into the cell or its influx to the intracellular medium ${ }^{28,31}$. Acute administration of calcium antagonists (felodipine) results in renal vasodilation, suggesting a calcium-sensitive vasoconstrictor mechanism of cyclosporine on the kidney ${ }^{22}$. Sander et al ${ }^{31}$ suggest a common molecular mechanism for cyclosporine immunosuppressive and hypertensive action. Calcineurin inhibition, indispensable for the cyclosporine immunosuppressive effect, could attenuate nitric oxide production and, thus, diminish its induced peripheral vasodilation.

Action on sympathetic activity is another mechanism that might explain cyclosporine-induced $\mathrm{SH},{ }^{7,34}$ and it was proposed based on the observation that cyclosporine increased renal concentration of catecholamines and sympathetic activity ${ }^{24}$. Cardiac denervation due to cardiac transplantation causes an increase in the sensitivity of beta-adrenergic receptors ${ }^{11}$, which results in an increment of sympathetic activation caused by cyclosporine ${ }^{24}$. Studies using intraneural microelectodes inserted selectively into muscle nerve fascicles of the fibular nerve 
showed that therapy with cyclosporine is associated with an increase in sympathetic activity in the fibular nerve of cardiac transplant recipients and patients with myasthenia gravis, and the magnitude of the effects is greater in transplanted patients ${ }^{24}$. Although studies in rats precisely localized the site of cyclosporine action on the autonomic nervous system (ANS), central and peripheral neural mechanisms may be involved ${ }^{35}$. It has been suggested that calcineurin may be an important cellular mediator in the cyclosporine-induced sympathetic activation ${ }^{31}$. Studies have shown that there is no change in plasmatic noradrenaline concentration of cardiac transplant recipients 9,14 and that renal vasoconstriction due to cyclosporine therapy is not associated with the increase of noradrenaline in the kidney ${ }^{14,21}$. One may, therefore, question whether the increase in sympathetic activity is responsible for cyclosporine-induced $\mathrm{SH}$.

BP increase in cardiac transplant recipients treated with cyclosporine is associated with a normal or slightly reduced cardiac output, along with an increased vascular resistance ${ }^{1,14}$. This peripheral vasoconstriction could be explained by the action of the renin-angiotensin-aldosterone system (RAAS). Cyclosporine acutely stimulates RAAS, elevating angiotensin II levels and causing renal vasoconstriction. Some aspects contradict this theory: $1^{\text {st }}$, this vasoconstriction persists after RAAS suppression ${ }^{15}$; $2^{\text {nd }}$, cyclosporine-induced SH has been associated with normal or diminished renin levels ${ }^{3,7,12-14,36,37} ; 3^{\text {rd }}$, long-term treatment with cyclosporine may partially block intrarenal conversion of inactive prorenin into active renin ${ }^{7}$; and finally, there is also plasmatic renin suppression, possibly secondary to the expansion of the liquid volume of the extracellular medium ${ }^{36}$. Equally, Bellet et al ${ }^{13}$ showed that cyclosporine does not stimulate the RAAS, and there is no difference in plasmatic renin levels in cardiac transplant recipients treated with cyclosporine, when compared with those treated with the conventional immunosuppressive therapy (azathioprine and prednisone). In addition, pretreatment with captopril does not prevent the reduction in the renal blood flow, suggesting that angiotensin II is not a mediator of cyclosporine-induced vasoconstriction ${ }^{7,13,19}$. Schaaf et $\mathrm{al}^{38}$, comparing the treatment with amlodipine and lisinopril in isolation, showed that amlodipine was more effective than lisinopril, suggesting that RAAS is not an $\mathrm{SH}$ determinant in these patients.

Another mechanism proposed to explain cyclosporine-induced $\mathrm{SH}$ is thromboxane $\mathrm{A} 2$ action. It was observed that cyclosporine diminishes prostaglandin levels $5,11,15,22$ and increases the synthesis of thromboxane A $2^{11,19,22,39}$, a powerful vasoconstrictor and platelet aggregation factor ${ }^{2}$. However, selective antagonists for thromboxane A2 partially reverse the vasoconstriction caused by cyclosporine ${ }^{15,21}$, increasing the glomerular filtration rate, but do not change blood pressure levels ${ }^{22}$. Prostaglandin selective inhibitors exacerbate renal vasoconstriction, suggesting that prostaglandins favor vasodilation ${ }^{15}$. Prostaglandins are produced by endothelial cells and are the main cyclooxygenase product. Their action, contrarily to thromboxane A2, is vasodilation and platelet antiaggregation ${ }^{2}$. Prostaglandin administration may reverse cyclosporine-induced vasoconstriction ${ }^{15}$. On the other hand, administration of nonsteroidal anti-inflammatory drugs (NSAIDs) increases cyclosporine-induced renal vasoconstriction, also suggesting the protective role of prostaglandins ${ }^{7}$. Therefore, a disorder in the balance between vasodilators and vasoconstrictors resulting from arachidonic acid could explain the cyclosporine effect ${ }^{2}$.

Endothelin (a substance produced by endothelial cells) action could be another mechanism by which cyclosporine might induce $\mathrm{SH}$. Studies in rats concluded that high doses of cyclosporine are associated with plasmatic endothelin activation, and that the administration of antiendothelin antibodies or antagonists of endothelin receptors may diminish renal vasoconstriction ${ }^{12,22,28,33}$. Although some studies suggest that cyclosporine elevates endothelin levels ${ }^{22,29}$, Edwards et al ${ }^{33}$ did not observe an increase in plasmatic endothelin in cardiac transplant recipients followed for a long time. Endothelin levels in transplanted patients receiving cyclosporine were similar to those in patients not receiving cyclosporine. However, one may not exclude the possibility of the occurrence of a local endothelin action without changes in its blood plasmatic levels ${ }^{33,40}$. Plasmatic endothelin concentration does not seem to be related to BP levels ${ }^{29}$.

Alterations in the balance between vasoconstrictor and vasodilator factors produced by the endothelium, such as endothelin, eicosanoids and EDRF (endothelium-derived relaxing factor) could contribute to changes in renal and systemic hemodynamics that occur during cyclosporine therapy ${ }^{22}$.

Other mechanisms have been proposed. Moderate hypomagnesemia is common during cyclosporine treatment and can contribute to $\mathrm{SH}^{19}$. An abnormal control from the central nervous system (CNS) over BP, due to cardiac denervation, has also been suggested. In these patients, there seems not to be reduction of blood pressure levels during sleep ${ }^{4,20,41}$; however, normalization of this circadian rhythm variability occurs some months after transplantation ${ }^{42,43}$.

Diversity of the proposed mechanisms indicates that there is not only one factor involved but a set of them determining renal vasoconstriction, glomerular filtration damage and peripheral vasoconstriction. Therefore, further studies are required to determine the mechanism through which cyclosporine leads to $\mathrm{SH}$ in cardiac transplant recipients.

\section{Hemodynamic alterations}

Mild to moderate hemodynamic alterations are common in asymptomatic cardiac transplant recipients using cyclosporine ${ }^{3,5,6,8,17,20}$. The relation between adverse effects of cyclosporine ( $\mathrm{SH}$ and renal failure) and hemodynamic abnormalities suggests cyclosporine may be responsible for these alterations ${ }^{1,6}$. Along with the hypervolemia caused by cyclosporine ${ }^{3,17}$, cardiac denervation ${ }^{1,7}$, myo- 
cardial disease (rejection and fibrosis) ${ }^{1,6-8}$, pericardial disease ${ }^{7}$, chronic tachycardia ${ }^{1}$, and obesity ${ }^{1}$ may explain the hemodynamic alterations that occur.

Studies have shown an increase in peripheral vascular resistance ${ }^{1,4,7}$ and normal cardiac output ${ }^{1,4,7,18}$ in patients with cyclosporine-induced SH after cardiac transplantation. Ventura et al ${ }^{1}$, however, showed that cardiac output and work are smaller, and peripheral vascular resistance and the degree of ventricular hypertrophy are greater in these patients than in those with essential SH.

Left ventricular hypertrophy is a powerful risk factor for the occurrence of cardiovascular complications. Left ventricle (LV) enlargement occurring in patients with essential SH produces a high risk for ventricular arrhythmias, systolic and diastolic dysfunction, as well as heart failure ${ }^{1}$. This can also be observed in patients with cyclosporine-induced $\mathrm{SH}$.

Compensatory LV hypertrophy is a normal adaptation response to $\mathrm{SH}$. It has been shown that essential $\mathrm{SH}$ is associated with structural and functional adaptations, which result in concentric LV hypertrophy. On the other hand, in cardiac transplant recipients with cyclosporineinduced SH, the ventricular mass increase is greater and is associated with a reduction in LV systolic function, leading to a decrease in ejection fraction ${ }^{1,4}$. The greatest determinants for LV hypertrophy in this situation seem to be weight and ventricular mass index, as well as BP levels ${ }^{1}$. In obese patients, in addition to hypertrophy, there is ventricular dilation secondary to an increase in the LV final diastolic volume, leading to diminishing systolic function. The presence of these hemodynamic abnormalities concomitant with obesity and SH may lead to unsuccessful cardiac transplantation in these patients 4 .

The causes of early occurrence of LV hypertrophy need to be cleared up. Biochemical alterations in cardiac muscle due to sudden preload increase ${ }^{17,18}$ and interstitial cellular edema secondary to ischemia during new heart implantation ${ }^{3,17,18}$ may be the factors involved. SH only contributes to worsening of left ventricular hypertrophy ${ }^{17,18}$. Early LV hypertrophy occurs equally in patients with or without rejection of the transplanted heart ${ }^{18}$. In spite of this, the correlation between the existence of myocardial fibrosis, hemodynamic alterations and plasmatic cyclosporine levels is still unknown ${ }^{6}$. There seems to be no relation between the hemodynamic abnormalities and the myocardial fibrosis observed through endomyocardial biopsy ${ }^{8}$. Further studies are necessary to determine the role of rejection and other factors (such as direct cyclosporine toxicity and adaptation of the patient to the transplanted heart) in the development of left ventricular hypertrophy and, therefore, hemodynamic alterations ${ }^{17}$.

Hemodynamic abnormalities occurring in cardiac transplant recipients are mostly due to the presence of cyclosporine-induced SH. Even though the cardiac function after transplantation is satisfactory in the short- and long-term ${ }^{3,6,8}$, SH plays an important role in the prognosis of these patients, requiring proper treatment ${ }^{3}$.

\section{Treatment}

The best treatment modality for the patient with cyclosporine-induced SH after cardiac transplantation has not yet been defined ${ }^{7,19}$. It is known that this kind of SH is, most of the time, difficult to clinically control, requiring the use of several powerful antihypertensive drugs ${ }^{7,23}$.

Administration of the smallest possible doses of cyclosporine and corticoids is recommended, aiming to facilitate antihypertensive treatment in transplanted patients ${ }^{7,19}$. Conventionally, more elevated cyclosporine doses are maintained only in the first 6 to 12 months after transplantation ${ }^{7,11}$. Renal function deterioration and BP level increase, however, are related more to the cyclosporine dose during this period. Cyclosporine dose reduction in the late postoperative period seems to have little influence on pressure levels ${ }^{7}$.

Different classes of antihypertensive drugs have been used in treatment of SH after cardiac transplantation; nonpharmacological treatment has been used as well. Even though there is no relationship between cyclosporineinduced SH and risk factors, such as hypertension, smoking, and hypercholesterolemia ${ }^{17}$, these factors should be controlled.

Ventura et al $^{4}$ emphasize the importance of weight loss in obese patients undergoing cardiac transplantation, in whom there is a high risk of unsuccessful transplantation, possibly due to a greater occurrence of hemodynamic alterations. It has been reported that blood pressure levels after transplantation are sensitive to sodium reduction in the diet ${ }^{28,32,37}$ but the BP reduction in these patients is smaller than in those with essential hypertension ${ }^{31}$. Further studies are required to evaluate the effectiveness of the nonpharmacological SH treatment in cardiac transplant recipients.

There are only a few trials comparing the effectiveness of different classes of antihypertensive drugs in SH treatment after transplantation ${ }^{31}$.

Calcium antagonists are effective drugs in SH treatment in patients treated with cyclosporine ${ }^{44,45}$ and seem to be the antihypertensives of choice ${ }^{22,25,28,46}$. Studies show that the early use of diltiazem (before, during or immediately after transplantation) is associated with a smaller incidence of episodes of rejection, as well as with a better function of the transplanted organ and a smaller incidence of coronary heart disease ${ }^{22,46}$. Calcium antagonists seem to have a protective effect on the kidney ${ }^{27}$, attenuating vasoconstriction produced by cyclosporine $28,38,47,48$, not increasing the glomerular filtration rate 22,45 , the renal plasmatic flow and the filtration fraction ${ }^{22}$. Experimental studies have shown that the same concentration that prevents the entrance of calcium into the renal tubule cells inhibits cyclosporine influx ${ }^{49}$. Diltiazem has the potential to elevate plasmatic cyclosporine levels ${ }^{28,50}$ and to diminish the immune response to the transplanted tissue ${ }^{27}$, thus making possible an immunosuppression with lower doses ${ }^{50}$. Nifedipine causes, as an adverse effect, heart rate increase and edema in some 
patients ${ }^{13}$. In addition, the combination of cyclosporine and nifedipine may result in an increase in gingival hyperplasia, when compared with therapy using cyclosporine only ${ }^{11}$. Cyclosporine levels should be carefully monitored when calcium antagonists are administered to cardiac transplant recipients with $\mathrm{SH}^{7}$. Due to the fact that calcium antagonists belong to a heterogeneous group of drugs, a greater number of studies are required to evaluate their effectiveness ${ }^{27}$.

Based upon the findings that renin levels are low or normal in these patients, that there is little renal ${ }^{38}$ and systemic response, and that there is the risk of hyperkalemia and the potential risk of acute renal deterioration during the treatment with angiotensin-converting enzyme inhibitors (ACEIs) solely or, more often, combined with diuretics, these drugs are generally avoided ${ }^{22,28}$. Experimental studies have shown that administration of these ACEIs does not acutely reverse the effects of cyclosporine on renal vessels ${ }^{13}$ and does not change BP levels and the glomerular filtration rate ${ }^{22}$. There are no reports on the increase in renal toxicity due to the concomitant use of ACEIs and cyclosporine ${ }^{7}$. A study ${ }^{7}$ analyzed the use of enalapril and furosemide in isolation, as well as in association with verapamil, showing an effective BP control for six months after transplantation in all groups. The authors suggested, however, the need for further trials to evaluate monotherapy with enalapril and association with verapamil. Mourad et al ${ }^{51}$ compared the use of lisinopril and nifedipine alone and in combination with furosemide and atenolol, for approximately 30 months, not finding any significant difference in the effects on BP and renal function. Effectiveness of ACEIs on BP progresses with time, perhaps as a result of renal vasodilation occurring over the long-term. Although only the effects of calcium antagonists and ACEIs were analyzed, it is important to emphasize that these drugs should be combined with low doses of beta-blockers and diuretics, respectively, in order to potentiate antihypertensive effectiveness and reduce adverse effects ${ }^{22}$. Almenar et al ${ }^{52}$ showed that fosinopril effectively controlled BP levels in cardiac transplant recipients. In addition, it significantly diminished the total cholesterol and LDL fraction (HDL fraction was not modified) in patients with these levels elevated. No disorders in hepatic and renal function were found. They have not made a conclusion, however, about the possible action of fosinopril on the atherosclerotic process of these patients.

Diuretics should be used carefully ${ }^{7,19}$ because the balance between hypertension/edema and hypovolemia/volume depletion is very narrow in cardiac transplant recipients with $\mathrm{SH}^{7}$. An increase in diuresis may potentiate the nephrotoxicity caused by cyclosporine ${ }^{21}$, reducing even more the renal blood flow and altering the pharmacokinetics of this immunosuppressive drug ${ }^{7,19}$. Diuretics may cause adverse effects, such as hypokalemia and hyperlipidemia ${ }^{46}$. In spite of this, the use of diuretics is justified in cardiac transplant recipients with $\mathrm{SH}$ probably due to the sodium retention and plasmatic volume increase occurring in these patients ${ }^{13}$.
In regard to beta-blockers, there are no studies examining the renal and antihypertensive effects of these drugs in this group of patients ${ }^{7}$.

Due to the possible sympathetic action in cyclosporine-induced SH in cardiac transplant recipients, clonidine or another sympatholytic agent seems to be a rational alternative to calcium antagonists and ACEIs ${ }^{31}$.

Ventura $^{2}$ and Andreassen et al ${ }^{53}$ analyzed the effectiveness of omega-3 fatty acids in cardiac transplant recipients with $\mathrm{SH}$ and showed that oral supplementation with $3 \mathrm{~g} /$ day and $4 \mathrm{~g} /$ day of this kind of fatty acid (with high concentration of eicosanoic and docosanoic acids) resulted in reduction of the peripheral vascular resistance and, therefore, BP levels.

Starling et al $^{7}$ believe that nonsteroidal anti-inflammatory drugs should be avoided in patients receiving cyclosporine. After 24 to $48 \mathrm{~h}$ of nonsteroidal anti-inflammatory drug administration, an increase in plasmatic creatinine and urea levels occurs. This renal dysfunction, however, is quickly reversed with the drug withdrawal. Acetylsalicylic acid, a powerful nonsteroidal anti-inflammatory drug that inhibits prostaglandin production, may potentiate cyclosporineinduced nephrotoxicity and SH. Concomitant administration of steroidal and nonsteroidal anti-inflammatory drugs may complicate the treatment due to their effect on blood volume and their interaction with antihypertensives ${ }^{21}$.

To use an immunosuppressive agent with equal or better effectiveness than cyclosporine, but without its toxic effects, would be the ideal therapy for preventing SH after cardiac transplantation ${ }^{31}$. Recently, new immunosuppressive drugs for transplanted patients have been studied, such as tacrolimus (FK506) and rapamycin ${ }^{31}$. FK506 has properties similar to those of cyclosporine but seems to cause greater renal and CNS toxicity ${ }^{54,55}$. It also induces $\mathrm{SH}$ after transplantation, which may be explained by its action on calcineurin, as occurs with cyclosporine. Rapamycin does not act upon this enzyme and its toxicity is still unknown because the studies are still going on. If the calcineurin hypothesis is correct, rapamycin may not cause $\mathrm{SH}$ and, pertaining to immunophilins, a class different from that of cyclosporine, these drugs may have a synergistic effect, making possible the reduction of the doses of both drugs and, therefore, their toxicity and effect on $\mathrm{BP}^{31}$.

Long-term clinical trials are required to determine the ideal treatment for $\mathrm{SH}$, as well as the smallest effective cyclosporine doses in the therapeutics of cardiac transplant recipients $1,6,19,21,46$.

\section{Prognosis}

In addition to neoplasias and coronary heart disease following transplantation, morbidity and mortality of cardiac transplant recipients are mostly due to side effects of cyclosporine, mainly SH and nephrotoxicity ${ }^{7}$. The incidence of complications in cardiac transplant recipients with $\mathrm{SH}$ is greater than that of patients with essential $\mathrm{SH}^{6}$. 
The survival of cardiac transplant recipients is $85 \%$ after one year, decreasing to $75 \%$ five years after the transplantation, but older patients ( $>50$ years) have lower survival than those being 20 to 49 years old ${ }^{11}$. Studies have shown that $90 \%$ of the patients surviving cardiac transplantation stayed in New York Heart Association type I functional class. Most of them reported a good quality of life ${ }^{11}$.
Improvement in the prognosis of transplanted patients is related to a greater knowledge of the natural history of the procedure and understanding of $\mathrm{SH}$ pathophysiology after transplantation. Based upon these, the ideal antihypertensive treatment to be instituted and the best cyclosporine dose for immunosuppression can be tested in multicenter clinical trials ${ }^{7}$.

\section{References}

1. Ventura HO, Lavie CJ, Messerli FH, et al. Cardiovascular adaptation to cyclosporine-induced hypertension. J Hum Hypert 1994; 8: 233-7.

2. Ventura HO, Milani RV, Lavie CJ, et al. Cyclosporine-induced hypertension. Circulation 1993; 88: 281-5.

3. Corcos T, Tamburino C, Léger P, et al. Early and late hemodynamic evaluation after cardiac tranplantation. J Am Coll Cardiol 1988; 11: 264-9.

4. Ventura HO, Johnson MR, Grusk B, Pifarre RP, Constanzo-Nordin MR. Cardiac adaptation to obesity and hypertension after heart transplantation. J Am Coll Cardiol 1992; 19: 55-9.

5. Frohlich ED, Ventura HO, Ochsner JL. Arterial hypertension after orthotopic cardiac transplantation. J Am Coll Cardiol 1990; 15: 1102-3.

6. Murali S, Uretsky BF, Reddy PS, Griffith BP, Hardesty RL, Trento A. Hemodynamic abnormalities following cardiac transplantation: relationship to hypertension and survival. Am Heart J 1989; 118: 334-41.

7. Starling RC, Cody RJ. Cardiac transplant hypertension. Am J Cardiol 1990; 65: 106-11.

8. Frist WH, Stinson EB, Oyer PE, Baldwin JSC, Shumway NE. Long-term hemodynamic results after cardiac transplantation. J Thorac Cardiovasc Surg 1987; 94: 685-93

9. Olivari MT, Antolick A, Ring S. Arterial hypertension in heart transplant recipients treated with triple drug immunossupressive therapy. J Heart Transplant 1989; 8: 34-9.

10. Austen WG, Cosimi AB. Heart transplantation after 16 years. N Engl J Med 1984; 311: 1436-8.

11. Reitz BA. Heart and heart-lung transplantation. In: Braunwald E-Heart Disease A Textbook of Cardiovascular Medicine. $5^{\text {th }}$ ed. Philadelphia: WB Saunders Co, 1992: 520-33.

12. Edwards BS, Loyd MA, Anderson LM. The synergistic effects of cyclosporine and endothelin - demonstration of an important cardiodepressor action. Transplantation 1993; 55: 8-11.

13. Bellet M, Cabrol C, Sassano P, Léger P, Corvol P, Ménard J. Systemic hypertension after cardiac transplantation: effect of cyclosporine on the renin-angiotensin-aldosterone system. Am J Cardiol 1985, 56: 927-31.

14. Kaye D, Thompson J, Jennings G, Esler M. Cyclosporine therapy after cardiac transplantation cause hypertension and renal vasoconstriction without sympathetic activation. Circulation 1993; 88: 1101-9.

15. Garr MD, Paller MS. Cyclosporine augments renal but not systemic vascular reactivity. Am J Physiol 1990; 258: 211-17.

16. Glanville AR, Baldwin JC, Hunt AS, Theodore J. Long-term cardiopulmonary function after human heart-lung transplantation. Aust NZ Med 1990; 20:208-14.

17. Farge D, Julien J, Amrein C, et al. Effect of systemic hypertension on renal function and left ventricular hypertrophy in heart transplant recipients. J Am Coll Cardiol 1990; 15: 1095-101.

18. Curtis MR, Uretsky BF, Kormos R, Hardesty RL, Griffith BP, Salerni R. Left ventricular hypertrophy in cyclosporine-induced systemic hypertension after cardiac transplantation. Am J Cardiol 1988; 62: 1140-2.

19. Bennet WM, Porter G. Cyclosporine -associated hypertension. Am J Med 1988; 85: 131-3.

20. Thompson ME, Shapiro AP, Johnsen AM, et al. The contrasting effects of cyclosporin-A and azatioprine on arterial blood pressure and renal function following cardiac transplantation. Intern J Cardiol 1986; 11: 219-29.

21. Porter GA, Bennet WM, Sheps SG. Cyclosporine-associated hypertension. Arch Internn Med 1990; 150: 280-3.

22. Mimran A, Mourad G, Ribstein J, Halimi JM. Cyclosporine-associated hypertension. In: Laragh JH, Brenner BM, eds - Hypertension: Pathophysiology, Diagnosis and Management. $2^{\text {nd }}$ ed. New York: Raven Press, 1995: 2459-69.

23. Weidle PJ, Vlasses PH. Systemic hypertension associated with cyclosporine: ewiew. Drug Intell Clin Pharm 1988; 22: 443-51.
24. Scherrer U, Vissing S, Morgan B, et al. Cyclosporine-induced sympathetic activation and hypertension after heart transplantation. NEngl J Med 1990; 323 : 693-9.

25. Ozdogan E, Banner N, Fitzgerald M, Musumeci F, Khaghani A, Yacoub M. Factors influencing the development of hypertension after heart transplantation. J Heart Transplant 1990; 9: 548-53.

26. Hardesty RL, Griffith BP, Debski RF, Bahson HT. Experience with cyclosporine in cardiac transplantation. Transplant Proc 1983; 15: 2553-8.

27. Weir WR. Therapeutic benefits of calcium channel blockers in cyclosporinetreated organ trasnplant recipients: blood pressure control and immunossupression. Am J Med 1991; 90(suppl 5A): 32S-6S.

28. Luke RG, Curtis JJ. Biology and treatment of transplant hypertension. In: Laragh JH, Brenner BM, eds - Hypertension: Pathophysiology, Diagnosis and Management. $2^{\text {nd }}$ ed. New York: Raven Press, 1995: 2471-81.

29. Haas GK, Woodin-Scott M, Binkley PF, Myerowitz PD, Kelley R, Cody RJ. Effects os successful cardiac transplantation on plasma endothelin. Am J Med 1993; 71: 237-40.

30. Bortolotto LA, Silva HB, Bocchi EA, Bellotti G, Stolf N, Jatene A. Evolução a longo prazo e complicações da hipertensão arterial após transplante cardíaco. Arq Bras Cardiol 1997; 69: 317-21.

31. Sander M, Victor RG. Hypertension after cardiac transplantation: pathophysiology and management. Curr Opin Nephrol Hypert 1995; 4: 443-51.

32. Curtis J, Luke R, Jones P, Diethelm A. Hypertension in cyclosporine-treated renal transplant patients is sodium dependent. Am J Med 1988; 85: 134-38.

33. Edwards BS, Hunt AS, Fowler MB, Valantine HA, Anderson LM, Lerman A. Effect of cyclosporine on plasma endothelin levels in humans after cardiac transplantation. Am J Cardiol 1991; 67: 782-4.

34. Sennesael JJ, Dupont AG, Verbeelen DL, Haelst LV. Hypertension and cyclosporine. Ann Intern Med 1986; 104: 729.

35. Lyson T, McMulllan DM, Ermel LD, Morgan BJ, Victor RG. Mechanism of cyclosporine-induced sympathetic activation and acute hipertension in rats. Hypertension 1994; 23: 667-75.

36. Bantle JP, Boudreau RJ, Ferris TF. Supression of plasma renin activity by cyclosporine. Am J Med 1987; 83: 59-64.

37. Singer DRJ, Markandu RGN, Bukley MG, et al. Blood pressure and endocrine responses to changes in dietary sodium intake in cardiac transplant recipients. Circulation 1994; 89: 1153-9.

38. Schaaf MR, Hené RJ, Floor M, Blankestijn PJ, Koomans HA. Hypertension after renal transplantation: calcium channel or converting enzyme blockade? Hypertension 1995; 25: 77-81

39. Coffman IM, Carr DR, Yarger WF, Klotman PE. Evidence that renal prostaglandins and thromboxane production is stimulated in chronic cyclosporine nophrotoxicity. Transplantation 1987; 43: 282-5.

40. Lerman AA, Hildebrand FLJ, Burnett JCJ. Endothelin has biologic action at physiologic and pathologic concentrations. J Am Soc Nephrol 1990; 1: 419.

41. Reeves RA, Shapiro AP, Thompson ME, Johsen AM. Loss of nocturnal decline in blood pressure after cardiac transplantation. Circulation 1986; 73: 401-8.

42. Lanuza DM, Grady K, Hetfleisch M, Johnson MR. Circadian rhytm changes in blood pressure and heart rate during the first year after heart transplantation. J Heart Lung Transplant 1994; 13: 614-23.

43. Borne P, Leerman M, Primo G, Degaute JP. Reappearance of a normal circadian rhytm of blood pressure after cardiac transplantation. Am J Cardiol 1992; 69: 794-801.

44. Ambrosi P, Bertucci B, Bertault-Péres, Métras D. Felodipine in hypertensive hert transplant recipients. J Heart Lung Transplant 1996; 15: 540-1.

45. Textor SC, SchwartzL, Wilson DJ, et al. Systemic and renal effects of nifedipine in cyclosporine-associated hypertension. Hypetension 1994; 23(suppl I): 220-4.

46. Curtis JJ. Management of hypertension after transplantation. Kidney Int 1993; 44(suppl 43): 45-9. 
47. Feehaly J, Walls J, Mistry N, et al. Does nifedipine ameliorate cyclosporin A nephrotoxicity. Br Med J 1987; 295: 310.

48. Epstein M. Calcium antagonists and renal protection: current status and perspectives. Arch Intern Med 1992; 152: 1573-84.

49. Nagineni CN, Misra BC, Lee DBN, Yanagawa N. Cyclosporine A-calcium channels interaction: a possible mechanism for nephrotoxicity. Transplant Proc 1987; 12: 1358-62.

50. Pochert JM, Pirson Y. Cyclosporine-diltiazem interaction. Lancet 1986; 1: 979.

51. Mourad G, Ribstein J, Mimram A. Coverting-enzyme inhibitor versus calcium antagonist in cyclosporine-treated renal transplants. Kidney Int 1993; 43: 419-25.

52. Almenar L, Osa A, Palencia M, Flores A, Sánchez E. Effects of fosinopril on the blood pressure and lipid profile of patients undergoing heart transplantation. J Heart Lung Transplant 1997; 16: 454-9.

53. Andreassen AK, Hartmann A, Offstad J, Geiran O, Kvernebo K, Simonsen S. Hypertension prophylaxis with ômega-3 fatty acids in heart transplant recipients. J Am Coll Cardiol 1997; 29: 1324-31.

54. European FK506 Multicenter Liver Study Group. Randomized trial comparing tracolimus (FK 506) and cyclosporine in prevention of liver allograft rejection. Lancet 1994; 344: 423-8.

55. The US Multicenter FK 506 Liver Study Group: A comparison of tracolimus(FK 506) and cyclosporine for immunossupression in liver transplantation. N Engl J Med 1994; 331: 110-15. 